\title{
Growth and Characterization of Strontium Chloride Added Nicotinic Acid Single Crystals
}

\author{
S. Chidambaram ${ }^{1}$, A. David Kalaimani Raj ${ }^{2}$, R'Punniyamoorthy ${ }^{3}$, R. Manimekalai ${ }^{4 *}$ \\ ${ }^{1,3,4}$ A.V.V.M. Sri Pushpam College (Autonomous), Poondi- 613 503, Tamilnadu, India \\ 2. BDUMC, Aranthangi, Pudukkottai (Dt), Tamilnadu, India \\ *Corresponding Author: (R. Manimekalai)Maniabi64@gmail.com , Tel.: +919942544718
}

Available online at: www.isroset.org

Accepted: 27/Jul/2018, Online: 31/Aug/2018

\begin{abstract}
Single crystals of strontium chloride added with Nicotinic acid were grown from aqueous solution by slow evaporation technique. The grown crystals are characterized by using single crystal XRD, FTIR spectroscopy, optical transmission, mechanical and photoluminescence spectral studies. As a result Single crystal XRD studies exposed that the crystal belongs to tetragonal system. The FTIR studies help to identify the functional groups which are present in the crystals. The optical transmission analysis shows that the crystal is transparent in the entire visible region. The cut off wavelength is $275 \mathrm{~nm}$. The sample is also subjected to photoluminescence analysis. Hardness was measured by the Vickers's hardness tester. The diamagnetic behavior of the grown crystal is confirmed by vibrating sample magnetometer.
\end{abstract}

Keywords - Crystal growth, single XRD, FTIR, optical studies, Mechanical strength, magnetic properties.

\section{INTRODUCTION}

The variety of applications of semiorganic materials in communication and optical usages result in the development of new Crystals. Due to good resistance, stability and higher transparency in the UV region shifted the researcher's attention make them to focuses towards new semi-organic crystals. The Strontium chloride $\left(\mathrm{SrCl}_{2}\right)$ is a salt of strontium and chloride. It forms neutral aqueous solutions. Strontium chloride is often used as a red coloring agent in pyrotechnics. Strontium Chloride is used for the medical treatment. It controls and prevents bone cancer and tooth sensitivity. It is soluble in water and the solubility in alcohol is not very great. Nicotinic acid also known as Niacin (Nicotinic acid + Vitamin) is an organic compound. It is a water-soluble vitamin, also known as vitamin $B_{3}$. Niacin is the generic term for nicotinic acid (pyridine 3-carboxylic acid) [1-4]. In recent times many NLO crystals are grown by the way of low temperature solution growth technique. The growth conditions were optimized for various concentrations and the results are compared with the parent materials. In this present research the growth of strontium chloride nicotinic acid (SCNA) single crystals have been grown by slow evaporation method. The crystals have been subjected to single crystal X-ray diffraction, UV-Vis-NIR and FTIR spectroscopic analyses. This crystal is also subjected to photoluminescence and hardness studies [5-9].

\section{RELATED WORK}

In the last few decades, researchers have aimed at finding high quality materials from the complex crystal family. There has been an enormous report directed towards the development of novel single crystals using the chemical compounds such as Strontium chloride and Nicotinic acid. The optical and electrical properties of Nicotinc acid doped KDP single crystals are reported by $\mathrm{B}$. Deepa and P. Philominathan, in the paper titled "Enhanced NLO and antipactrial properties of nicotinic acid doped- KDP crystals: synthesis, growth and characterization". In this present work, the Strontium chloride added with Nicotinic acid (SCNA) to grow a novel single crystal. The grown crystal is subjected to study its cell parameters, optical and mechanical properties. From the observed results, their characteristics are analyzed in this work.

\section{Materials AND MethodS}

The strontium chloride added nicotinic acid single crystals were synthesized by using Analar grade strontium chloride and nicotinic acid. They were added in the ratio $1: 1$, in doubly distilled water. The solution is stirred; it stirred by well using a magnetic stirrer, then the solution is filtered using filter paper and kept in a dust free environment. Slow evaporation of the solvent produced strontium chloride nicotinic acid (SCNA) single crystals takes place in the time 
span of $15-20$ days. Good transparent single crystals are harvested and are shown in Figure.1

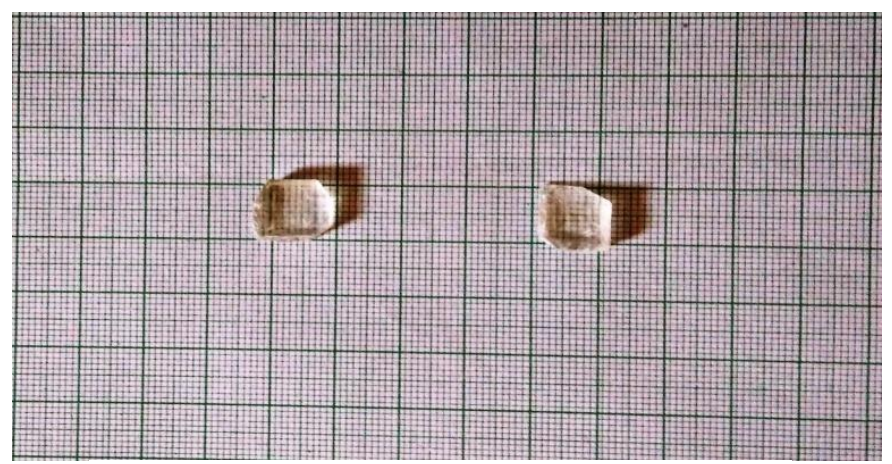

Figure- 1. Strontium chloride nicotinic acid (SCNA) crystal

\section{RESUlts AND Discussion}

\subsection{Single crystal $X$-ray diffraction}

The grown (SCNA) crystals were subjected to single crystal X-ray diffraction analysis using ENRAF NONIUS CAD4 Xray diffractometer to determine the cell parameters which exposes that the strontium chloride nicotinic acid crystallize in monoclinic system. The lattice parameters were found to be $a=6.318(\AA), b=10.549(\AA), c=6.037(\AA), \alpha=\gamma=90^{\circ}, \beta=$ $112.97^{0} \mathrm{~V}=387.1 \AA$

\subsection{Fourier Transform infrared (FTIR) analysis}

FTIR spectrum of the grown (SCNA) crystal is shown in Fig (2). It was recorded on Perkin Elmer FT-IR Spectrophotometer within the wave number range in the $4000-400 \mathrm{~cm}^{-1}$. The broad $\mathrm{OH}$ stretching absorption appears nearly at $3391 \mathrm{~cm}^{-1}$. The peaks at 1598 and $1481 \mathrm{~cm}^{-1}$ are due to the $\mathrm{C}-\mathrm{C}$ bond $\mathrm{C}=\mathrm{C}$ stretching. The $\mathrm{C}=\mathrm{N}$ strong stretching appear at $1193 \mathrm{~cm}^{-1}[10-11]$. The C-H out of plane bending vibrations is observed at $1032 \mathrm{~cm}^{-1}$. A band occurring around $574 \mathrm{~cm}^{-1}$ corresponds to $\mathrm{C}-\mathrm{C}-\mathrm{O}$ deformation [10-11].

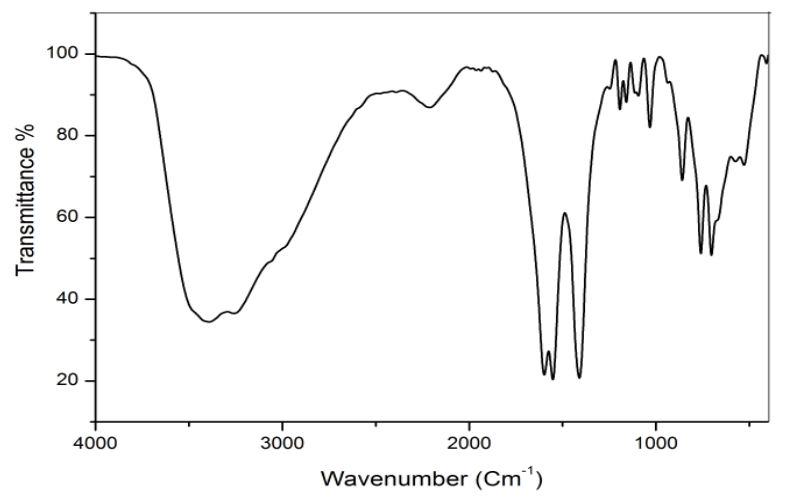

Figure-2. FTIR Spectrum of SCNA crystal
Table 1. Functional group assignment of SCNA crystal

\begin{tabular}{|l|l|}
\hline Wave number in $\mathbf{~ c m}^{-1}$ & Assignments \\
\hline 3391,3258 & $\begin{array}{l}\text { OH stretching of } \mathrm{COOH} \\
\text { absorption }\end{array}$ \\
\hline 2210 & $-\mathrm{C} \equiv \mathrm{C}$ - stretching \\
\hline 1598 & $\mathrm{~N}-\mathrm{H}$ bending \\
\hline 1552,1488 & $\mathrm{C}=\mathrm{C}$ stretching \\
\hline 1193 & $\mathrm{C}=\mathrm{O}$ stretching \\
\hline 1159,1094 & $\mathrm{C}-\mathrm{N}$ stretching \\
\hline 1032 & $\mathrm{C}-\mathrm{H}$ out-of-plane bending \\
\hline 859 & $=\mathrm{C}-\mathrm{H}$ bending \\
\hline 759,703 & $\mathrm{C}-\mathrm{Cl}$ stretching \\
\hline 574 & $\mathrm{O}-\mathrm{C}-\mathrm{O}$ deformation \\
\hline 528 & $\mathrm{COO}{ }^{-}$In-plane-bending \\
\hline
\end{tabular}

\subsection{UV-Vis- NIR spectral studies}

The UV-Vis-NIR spectral studies are mainly used to assess the optical applications of the grown crystals. The Fig. 3 shows the transmittance spectrum of grown crystal. From the spectrum, SCNA crystal exposes lower cut-off wavelength around $275 \mathrm{~nm}$. The spectrum also indicates the applicable transmission of the crystal elongate from 300 to $1100 \mathrm{~nm}$ which makes the crystals valuable for the applications requiring blue/green light. The high transmittance in the entire visible region enables it to be a good one for optoelectronic applications [12]. From Tau's plot, the calculated band gap energy is $4.5 \mathrm{eV}$ and is shown in Fig (4).

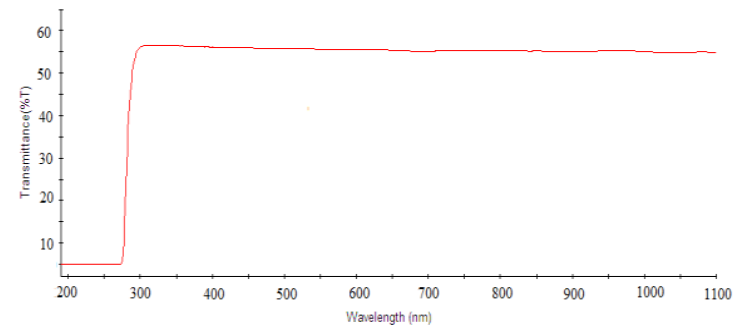

Figure-3. Optical Transmittance of SCNA crystal

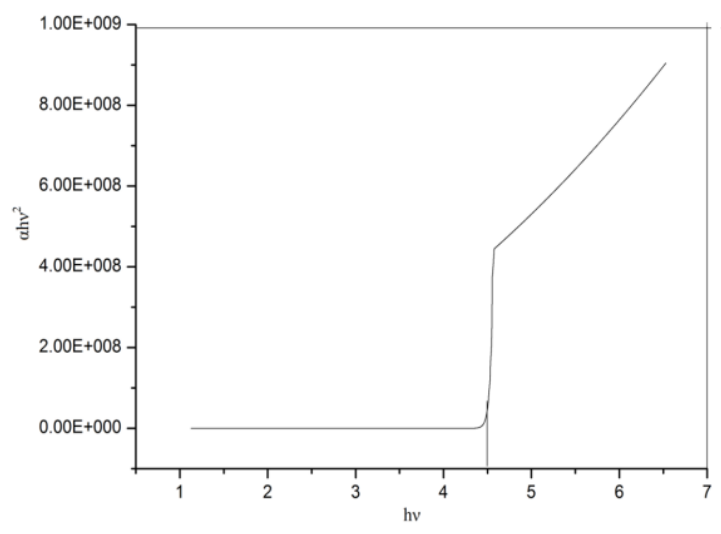

Figure - 4. Tauc's plot of SCNA crystal 


\subsection{Photoluminescence studies}

Photoluminescence comprises both fluorescence and phosphorescence processes and originates from an absorption/emission process between different electronic energy levels in the material.

The PL spectrum recorded using crystal indicates LS45. The sharp peak in the spectrum shows the purity and crystalline nature of the grown crystal. The peak at $453 \mathrm{~nm}$ indicates the sample suited for optoelectronic applications [13]. Also it indicates that the crystal may possess the frequency doubling capacity. The other peaks at 490 and $681 \mathrm{~nm}$ indicate the proper coordination of strontium chloride with nicotinic acid.

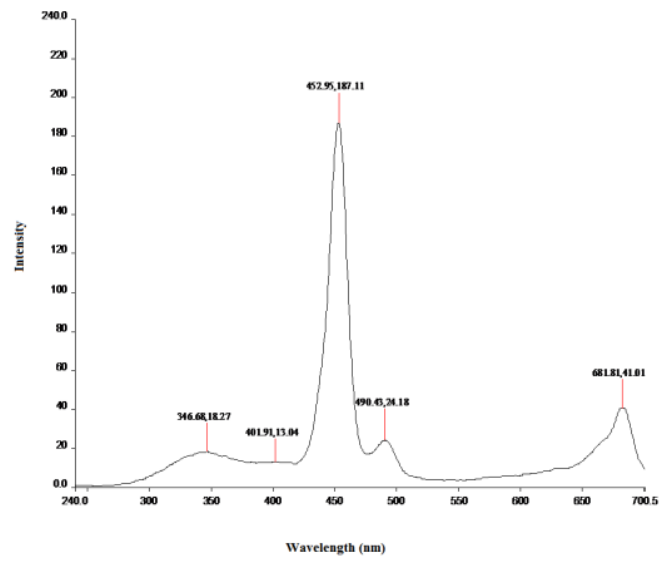

Figure - 5. Photoluminescence spectrum of SCNA crystal

\subsection{Hardness studies}

The mechanical property of the grown crystal was analyzed using LEITZ tester fitted with a Vicker's diamond rhombus indenter. The well powdered form of the crystal was placed on the rostrum of Vickers microhardness tester and the loads of different magnitudes were applied in fixed intervals of time. The depression time was kept as $5 \mathrm{~s}$ for all the loads. The Vicker's hardness number of the grown crystal was calculated from the relation

$$
\mathrm{Hv}=(1.854 \mathrm{xP}) / \mathrm{d}^{2} \mathrm{~kg} / \mathrm{mm}^{2}
$$

Where Hv is the Vicker's hardness number in $\mathrm{kg} / \mathrm{mm}^{2}$, $\mathrm{P}$ is the applied load in $\mathrm{kg}, \mathrm{d}$ is the average diagonal length of the indentation mark in $\mathrm{mm}$.

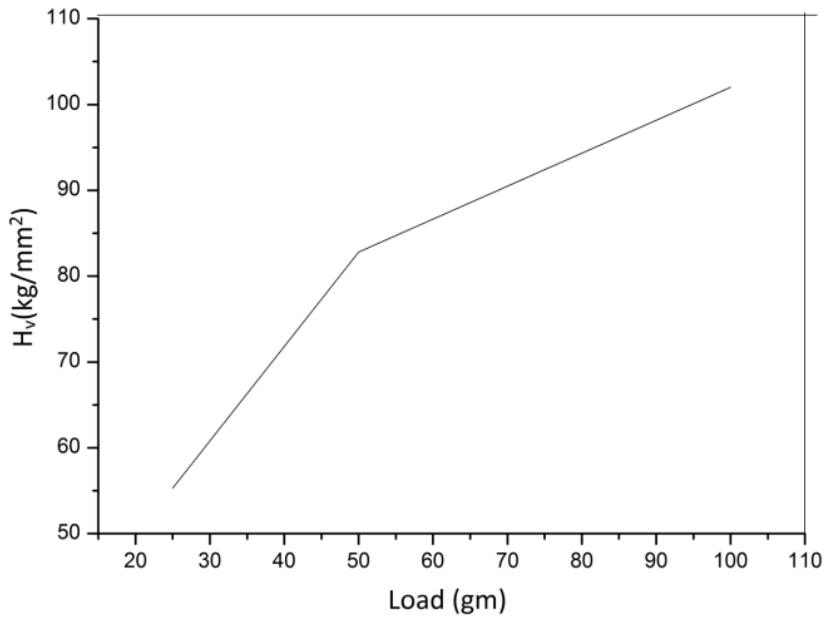

Figure - 6. Load P and Vs Hardness number of SCNA crystal

A graph was plotted between hardness number $(\mathrm{Hv})$ and applied load $\mathrm{P}$ as shown in Fig .6. From the graph it was found that hardness value increases with increase in load [14]. In order to find the work hardening coefficient, a graph was plotted between $\log \mathrm{p}$ and $\log \mathrm{d}$. A linear graph is obtained and is shown in Fig .7. From this observation it can be found as the mechanical quality of the material. The slope of the line gives the work hardning co-efficient. From the slope value, it is concluded that the material belongs to hard category.

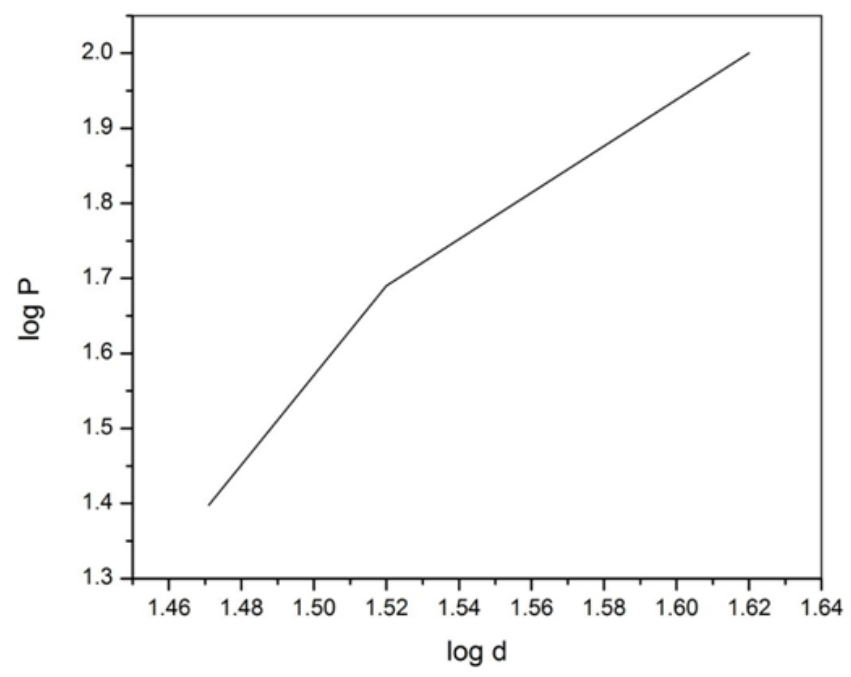

Figure - 7. $\log p$ vs $\log d$ 


\subsection{VSM}

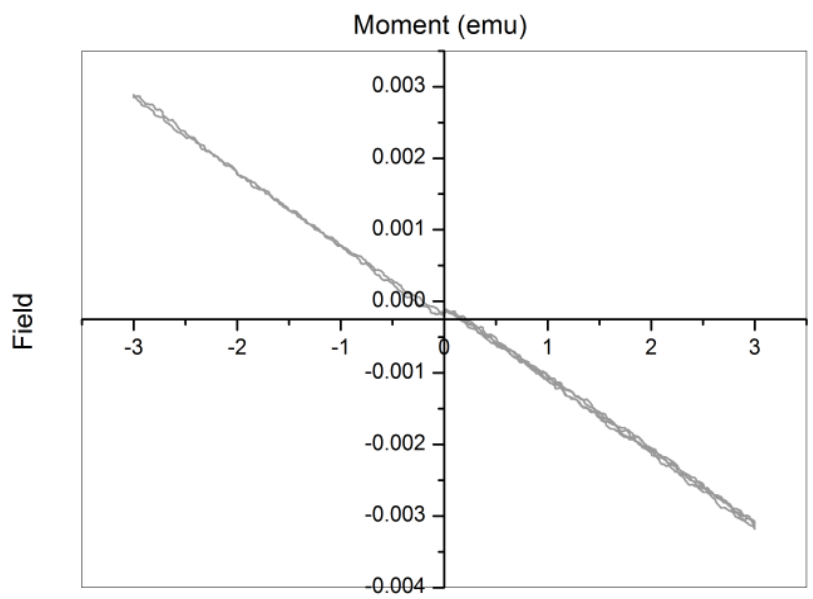

Figure - 8. Hysteresis loop of the grown SCNA crystal.

Vibrating sample magnetometer systems are used to measure the magnetic properties of materials as a function of magnetic field. They are ideally suited for research and development, production testing, quality and process control. In the present case, the magnetic study was carried out using a vibrating sample magnetometer CR155 quantum design. A plot of typical magnetic moment Vs magnetic field, hysteresis path traced at room temperature for the grown crystal as shown in Fig.7. It is observed from the graph that the sample SCNA is exhibiting the diamagnetic behavior [15].

\section{CONCluSion AND FUtURE SCOPE}

The single crystal of strontium chloride nicotinic acid NLO material has been grown by slow evaporation technique. The single crystal XRD analysis confirms the structure of the crystal as monoclinic system. Functional groups and modes of vibration were identified from FT-IR spectrum. The lower cut off wavelength is determined using UV- VIS- NIR spectrum of the grown SCNA crystal is studied. The photoluminescence spectrum is recorded for the grown SCNA crystal. From these studies, this crystal is well suited for optoelectronic applications. Mechanical properties are clarified by Vickers hardness test. The VSM graph confirms the diamagnetic nature of the grown crystal.

\section{ACKNOWLEDGMENT}

The authors acknowledge St. Joseph's College, Trichy, India for spectral facilities. The authors gratefully acknowledge the Sophisticated Analytical Instrument Facility, Indian Institute of Technology Madras, Chennai, India, for the XRD studies.

\section{REFERENCES}

[1] B. Deepa and P. Philominathan, "Investigation on the optical, mechanical and magnetic properties of organic NLO single crystal: Pyridine 3-carboxylic acid" Optik, Vol. 127, PP.8698-8705, 2016.

[2] S.B. Monaco, et al., "Synthesis and characterization of chemical analogs of L-arginine Phosphate”, J. crys. Growth 85 (1), 252-255, (1987)

[3] D. S. Chemla, J. Zyss, "Nonlinear Optical properties of Organic Molecule and Crystals", Academic, New York, (1987).

[4] R. Goplakrishnan, P. Ramasamy, Proceedings of the international workshop on crystal "Growth and Characterization of Technology important Materials”, India. P.23, 2004.

[5] Arora S.K., Vipul Patel, Bhupendra Chudasama and Brijesh Amin "Single crystal growth and characterization of strontium tartrate," J. Cryst. Growth, Vol. 275, pp.e657e661, 2005.

[6] Elvehjem C.A. and Teply L.J. "The Structure and Estimation of Natural Products Functionally Related to Nicotinic Acid," Chem. Rev. Vol. 33, pp. 185-208, 1943.

[7] Gille A., Bodor E.T., Ahmed K. and Offermarms S. "Nicotinic acid: pharmacological effects and mechanisms of action," Ann. Rev. Pharmacol. Toxicol. Vol. 48, pp.79-106, (2008).

[8] Dhanaraj P.V. and Rajesh N.P. "Investigations on crystal growth, structural, optical, dielectric, mechanical and thermal properties of a novel optical crystal: Nicotinium nitrate monohydrate," J. Cryst. Growth, Vol.318, pp. 974978, 2011.

[9] Jun Shen, Jimin Zheng, Yunxia Che and Bin Xi "Growth and properties of organic nonlinear optical crystals: L-tartaric acid-nicotinamide and D-tartaric acid-nicotinamide," J. Cryst. Growth, Vol. 257, pp. 136-140 (2003).

[10] B. Deepa and P. Philominathan, "Enhanced NLO and antipactrial properties of nicotinic acid doped- KDP crystals: synthesis, growth and characterization," Material Research innovations, Vol.21, 2017.

[11] S. K. Bachhav, N.S. Patil, M.S. Kale and D.S. Bhavsar. "Crystal growth and characterization of strontium doped barium tartrate crystals by silica gel method," Advance in applied science Research. Vol.5(6), pp. 66-71, 2014

[12] K. Srinivasan, P. Ramasamy, A. Cantoni and G. Bocelli, "Mixed crystals of $\mathrm{NH}_{4} \mathrm{H}_{2} \mathrm{PO}_{4}-\mathrm{KH}_{2} \mathrm{PO}_{4}$ : Compositional Dependence of Morphology, Microhardness and Optical Transmittance," Material Science and Engineering: B, Vol.52, No2-3,pp.129-133, 1998.

[13] Anandan P.,Vetrivel S., Jayavel R., Vedhi C., Ravi G. and Bhagavannarayana G. "Crystal growth, structural and photoluminescence studies of L-tyrosine hydrobromide semi organic single crystal," J. Phys. Chem. Solids, Vol. 73, pp. 1296- 1301 (2012). 
[14] M. Iyanar, J. Thomas, Joseph prakash, C. Muthamizhchelvan, S. Ekadevasena, and Shek Dhavud, Material science Research: india, Vol.2(1), pp.22-27, 2015.

[15] G. Pasupathi, K.Uma, C. Ramachandra Raja, and R. Manimekalai, "Influence of ethylene diamine tetra acetic acid on the performance of ferrous sulfate hepta hydratenon linear optical single crystal”, Materials Letters, Vol.161, pp. 224-226, 2015.

\section{AUTHORS PROFILE}

Dr. R. Manimekalai pursed M.Sc., M.Phil., and Ph.D from Bharathidasan University, Tiruchirappalli in 1988, 1989 and 2014. Presently working as an Associate professor of Physics, A.V.V.M. Sri Pushpam College, Poondi, Thanjavur-613 503, Tamil Nadu, India. Having 29 years of teaching and research experience in UG, PG and M.Phil., level. Acting as research advisor in physics from the year 2016 onwards in A.V.V.M. Sri Pushpam College (Autonomous), Poondi, Thanjavur (affiliated to Bharathidasan University). Published more than 12 research papers in reputed, peer reviewed, citation indexed international journals (Elsevier, Springer, Science direct) and international level conference. At present guiding eight Ph.D and six M.Phil research Scholars.

Mr. S. Chidambaram pursed Bachelor of Science and Master of Science, in Government Arts College, Udhagamandalam, Tamil Nadu, India and Bharathiar university Coimbatore respectively, in 2011, 2014, and M.Phil., in A.V.V.M. Sri Pushpam College, Poondi, Thanjavur, Tamil Nadu, India and Bharathidasan University, Tiruchirappalli respectively, in 2016. He is currently pursuing Ph.D as a Full- time research scholar in the A.V.V.M. Sri Pushpam College (Autonomous), Poondi, Thanjavur (affiliated to Bharathidasan University) Tamil Nadu, India. His main research work focuses on Material science.

Mr. A. David Kalaimani Raj pursed Bachelor of Science, Master of Science and M.Phil., in A.V.V.M. Sri Pushpam College, Poondi, Thanjavur-613503, Tamil Nadu, India and Bharathidasan University, Tiruchirappalli respectively, in 2002, 2004 and 2005. $\mathrm{He}$ is currently pursuing $\mathrm{Ph} . \mathrm{D}$ as a part- time research scholar in the A.V.V.M. Sri Pushpam College (Autonomous), Poondi, Thanjavur (affiliated to Bharathidasan University) and currently working as an Assistant professor in Physics, Bharathidasan University model college, Aranthangi, Pudukkottai (Dt), Tamil Nadu, India. His main research work focuses on Material science. He has 15 years of teaching and research experience in UG and PG level.

Mr. R. Punniyamoorthy pursed Bachelor of Science, Master of Science and M.Phil., in A.V.V.M. Sri Pushpam College, Poondi, Thanjavur-613503, Tamil Nadu, India and Bharathidasan University, Tiruchirappalli respectively, in 2008, 2010 and 2013. $\mathrm{He}$ is currently pursuing Ph.D as a part- time research scholar in the A.V.V.M. Sri Pushpam College (Autonomous), Poondi, Thanjavur (affiliated to Bharathidasan University) and currently working as an Assistant professor in Physics, Kurinji college of Engineering and Technology, manapparai, Tamil Nadu, India. His main research work focuses on Material science. He has 6 years of teaching and research experience in UG and PG level. 